(JAFI)

\title{
OPTIMASI CARBOPOL 940 DAN GLISERIN PADA GEL TANAMAN ANTING-ANTING (Acalypha indica L.) SEBAGAI ANTIOKSIDAN
}

\author{
OPTIMATION OF CARBOPOL 940 AND GLYCERIN OF TANAMAN ANTING-ANTING (Acalypha \\ indica L.) GEL AN ANTIOXIDANT
}

\author{
Prayoga Fery Yuniarto ${ }^{1}$, Mujtahid Bin Abd Kadir ${ }^{2}$ \\ 1,2 Jurusan Farmasi, Universitas Kadiri, Kediri \\ Penulis Korespondensi: \\ Prayoga Fery Yuniarto \\ Jurusan Farmasi, Universitas Kediri, Kadiri \\ prayoga@unik-kediri.ac.id
}

\begin{abstract}
ABSTRAK
Tanaman anting-anting (Acalypha indica L.) diduga memiliki khasiat sebagai antioksidan. Penggunaan tanaman anting-anting untuk pemakaian topikal kurang praktis, sehingga dibuat sediaan gel. Kemudian gel dilakukan optimasi dengan metode Simplex Lattice Design agar dihasilkan formula yang optimum sehingga dihasilkan gel antioksidan yang stabil. Penelitian ini bertujuan untuk mengetahui khasiat gel optimum tanaman anting-anting sebagai antioksidan. Ekstrak maserasi dibuat sediaan gel menggunakan basis carbopol 940 (A) dan gliserin (B) sehingga didapat 3 formula, yaitu F1 (100\% A), F2 (50\% A, 50\% B), dan F3 (100\% B) lalu dioptimasi berdasarkan sifat fisik viskositas, daya lekat, dan daya sebar. Metode optimasi Simplex Lattice Design menggunakan program design-expert 8.0.6.1. Gel optimum diuji akitivitas antioksidan dengan menggunakan metode DPPH. Aktivitas antioksidan dihitung dengan cara menentukan $\lambda$ maksimum dan operating time sehingga didapat nilai $\mathrm{IC}_{50}$ melalui analisa probit dengan digunakan vitamin $C$ sebagai pembandingnya. Kombinasi optimum antara carbopol 940 dan gliserin sebagai basis pada pembuatan gel ekstrak Tanaman anting-anting (Acalypha indica L.) dengan metode Simplex Lattice Design yaitu Carbopol sebesar 1,18 g dan gliserin sebesar $3,82 \mathrm{~g}$. Hasil uji-t viskositas, daya lekat, daya sebar menunjukkan tidak ada beda signifikan. Hasil yang diperoleh menunjukkan gel optimum tanaman anting-anting mempunyai aktivitas antioksidan dengan harga $\mathrm{IC}_{50}$ sebesar $164,58 \mathrm{ppm}$.
\end{abstract}

Kata Kunci: antioksidan, carbopol 940, gliserin, Simplex Lattice Design, tanaman anting-anting 


\title{
JURNAL INOVASI \\ FARMASI INDONESIA
}

(JAFI)

\begin{abstract}
Acalypha indica $\mathrm{L}$, is suspected has an antioxidant. The use of anting-anting directly considered less practical, so that it made the gel preparations. And then it use optimation by Simplex Lattice Design method so get the most optimum antioxidant gel. This research purpose for know the efficacy of apple optimation gel as an antioxidant. Maceration extract made of gel with components carbopol 940 (A) and glycerin (B) so that get three formulas, F1 (100\% A), F2 (50\% $A, 50 \% \mathrm{~B})$, dan $\mathrm{F3}(100 \% \mathrm{~B})$ and then optimation by viscosity, adhesion, and dispersive power. Simplex Lattice Design method with use program design-expert 8.0.6.1. Research antioxidant activity of optimum gel by method of DPPH. Antioxidant activity calculated by $\lambda$ maximum and operating time so that get $I C_{50}$ values by probit analysis. Optimation mixture between carbopol 940 and gliserin as components is carbopol 1.18 and glycerin 3.82. The resulted of $t$-test of viscosity, adhesion, and dispersive power showed no significant difference between the predictions with actual experimental result. The result showed optimum gel of apple fruit has antioxidant activity amounted to $164.58 \mathrm{ppm}$.
\end{abstract}

Keywords: antioxidant, carbopol 940, glycerin, Simplex Lattice Design, Acalypha indica L.

\section{PENDAHULUAN}

Indonesia merupakan negara yang memiliki berbagai jenis tanaman yang berkhasiat sebagai obat, baik dari jenis buah-buahan, sayur-sayuran, rempah-rempah, tanaman pangan maupun tanaman yang tumbuh liar di sekitaran. Tanaman yang berpotensi memiliki khasiat sebagai antioksidan adalah tanaman tanaman anting-anting (Acalypha indica L.). Ekstrak tanaman anting-anting memiliki senyawa aktif yang memiliki potensi antioksidan (Lisdawati, 2002). Menurut Halimah (2010) penelitian tanaman Anting-anting dengan variasi pelarut yaitu etanol, kloroform dan n-heksana menunjukkan bahwa adanya golongan senyawa flavonoid (dalam ekstrak etanol), steroid (dalam ekstrak kloroform) dan triterpenoid (dalam ekstrak etanol dan n-heksana).

Penggunaan senyawa antioksidan baik secara sistemik maupun lokal semakin digemari karena dipercaya dapat menghambat dan menetralisir terjadinya reaksi oksidasi yang melibatkan radikal-radikal bebas (Ismail et al., 2014). Paparan sinar matahari berlebih merupakan salah satu faktor yang dapat menghasilkan radikal bebas dan menyebabkan berbagai kerusakan struktur kulit serta menurunkan respon imun. Pengaruh negatif dari radikal bebas dapat dihambat dengan antioksidan salah satunya dengan penggunaan bahan alam atau obat tradisional (Rahmadhani, 2017).

Formulasi ekstrak tanaman anting-anting dalam sediaan gel dalam basis carbopol dan gliserin digunakan untuk meningkatkan efektivitas penggunaan tanaman anting-anting pada kulit. Gliserin dapat berfungsi sebagai pengawet, antimikroba, emolien, humektan, dan meningkatkan viskositas (Rowe et al., 2006).

Usaha pengembangan dalam penelitian ini yaitu dibuat bentuk sediaan gel sehingga lebih praktis dalam pemakaiannya untuk menangkal radikal bebas. Lalu dilakukan optimasi agar dihasilkan formula yang paling optimum sehingga dihasilkan gel antioksidan yang stabil. 


\section{JURNAL INOVASI \\ FARMASI INDONESIA}

(JAFI)

\section{TUJUAN PENELITIAN}

Tujuan penelitian ini yaitu untuk mengetahui berapakah kombinasi yang optimum antara carbopol 940 dan gliserin sebagai basis pada pembuatan gel ekstrak tanaman anying-anting dengan metode Simplex Lattice Design dan untuk mengetahui berapakah $\mathrm{IC}_{50}$ dari gel tanaman anting-anting dengan komposisi optimum terhadap radikal bebas DPPH (1,1-difenil-2pikrilhidrazil).

\section{METODE}

\section{Bahan}

Bahan yang digunakan dalam penelitian ini adalah tanaman anting-anting yang diperoleh di Kelurahan Pojok, Kecamatan Mojoroto, Kota Kediri, Jawa Timur, etanol 70\%, carbopol 941, gliserin, DPPH, trietanolamin, metil paraben, karboksimetil selulosa, aquades, metanol p.a.

Alat

Alat-alat yang digunakan dalam penelitian ini adalah gelas ukur, beaker glass, Erlenmeyer, tabung reaksi, corong kaca, ayakan no. 40, oven, botol maserasi, wadah gel, viscometer Rion VT-04, mortir dan stamfer, alat uji daya lekat, alat uji daya sebar, water bath, vacuum rotary evaporator dan alat uji $\mathrm{pH}$.

\section{Pembuatan Serbuk}

Sebanyak $2 \mathrm{~kg}$ tanaman anting-anting yang telah kering setelah dioven diserbuk dengan mesin penyerbuk, kemudian diayak dengan ayakan no. 40. Serbuk yang tidak terayak dihaluskan lagi sampai semua serbuk terayak. Setelah itu serbuk ditimbang lagi untuk menentukan perhitungan bobot persen kering terhadap bobot basah.

\section{Pembuatan Ekstrak Etanol Tanaman Anting-Anting}

Menimbang 100 gram serbuk kering lalu dimasukkan ke dalam botol $1000 \mathrm{~mL}$ dan ditambah $750 \mathrm{~mL}$ pelarut etanol 70\%. Campuran serbuk kering dan etanol 70\% ditutup dan disimpan selama 5 hari dengan sesekali dikocok 3 kali sehari berulang-ulang (Voigt, 1995), kemudian disaring dengan kain flanel lalu pelarut diuapkan dalam vakum rotary evaporator dengan suhu $40{ }^{\circ} \mathrm{C}$ sampai diperoleh ekstrak kental.

\section{Identifikasi Kandungan Kimia Ekstrak Etanol Tanaman Anting-Anting}

Identifikasi senyawa dengan KLT pada penelitian kali ini dilakukan pada ekstrak tanaman anting-anting.

Tabel 1. Identifikasi Dengan Kromatografi Lapis Tipis (KLT)

\begin{tabular}{|c|c|c|c|c|c|}
\hline Senyawa & Fase diam & Fase gerak & $\begin{array}{l}\text { Pereaksi } \\
\text { semprot }\end{array}$ & Hasil pustaka & Daftar pustaka \\
\hline Vitamin C & $\begin{array}{l}\text { Silika gel } \\
\text { GF } 254\end{array}$ & $\begin{array}{l}\text { n- butanol : asam } \\
\text { asetat : air }(4: 1: 5)\end{array}$ & Dragendorf & Orange & Depkes 1992 \\
\hline Flavonoid & $\begin{array}{l}\text { Silika gel } \\
\text { GF } 254\end{array}$ & $\begin{array}{l}\text { n- butanol : asam } \\
\text { asetat : air }(4: 1: 5)\end{array}$ & $\begin{array}{l}\text { Larutan sitro } \\
\text { borat }\end{array}$ & Kuning & Hartanti 2008 \\
\hline Tanin & $\begin{array}{l}\text { Silika gel } \\
\text { GF } 254\end{array}$ & $\begin{array}{l}\text { n- heksan: etil asetat } \\
(3: 7)\end{array}$ & $\mathrm{FeCl}_{3} 1 \%$ & $\begin{array}{l}\text { Kuning } \\
\text { kehitaman }\end{array}$ & Depkes 1987 \\
\hline
\end{tabular}

\section{Pembuatan Sediaan Gel}

CMC dikembangkan dalam aquadest panas 20 kalinya pada beaker glass. Nipagin dilarutkan dengan aquadest dalam mortir dan ditambahkan gliserin, diaduk sampai homogen. Carbopol 940 


\section{JURNAL INOVASI \\ FARMASI INDONESIA}

(JAFI)

ditambahkan pada campuran tersebut sambil terus diaduk dengan cepat. Hasil pengembangan CMC dan trietanolamin ditambahkan ke dalam campuran, lalu diaduk dengan pengadukan ringan sampai diperoleh massa gel yang transparan. Ditambahkan ekstrak tanaman anting-anting dan sisa aquadest ke dalam campuran, lalu diaduk sampai didapatkan sediaan gel yang homogen.

Tabel 2. Rancangan Formula Sediaan Gel Tanaman Anting-Anting Secara SLD

\begin{tabular}{lccc}
\hline \multirow{2}{*}{ Bahan } & Formula I & Formula II & Formula III \\
\cline { 2 - 4 } & $(\mathrm{g})$ & $(\mathrm{g})$ & $(\mathrm{g})$ \\
\hline tanaman anting-anting & 10 & 10 & 10 \\
\hline Carbopol 940 & 5 & 2,5 & 0 \\
\hline Gliserin & 0 & 2,5 & 5 \\
\hline trietanolamin & 0,5 & 0,5 & 0,5 \\
\hline Metil paraben & 0,2 & 0,2 & 0,2 \\
\hline CMC & 2 & 2 & 2 \\
\hline aquadest & 82,3 & 82,3 & 82,3 \\
\hline Berat gel & 100 & 100 & 100 \\
\hline
\end{tabular}

Pengujian Stabilitas Fisik Gel Optimum Ekstrak Tanaman Anting-Anting

1. Uji Organoleptis. Uji dilakukan dengan pengamatan visual meliputi perubahan warna, bau (ketengikan), konsistensi, dan terjadinya pemisahan fase (Purwanto, 2013).

2. Uji Homogenitas Gel. Uji dilakukan dengan pengamatan visual dengan cara sediaan hidrogel dioleskan pada kaca transparan/ lempeng kaca dimana sediaan diambil 3 bagian yaitu atas, tengah dan bawah, kemudian dilihat warnanya seragam atau tidak dan tidak adanya butiran kasar (Purwanto, 2013).

3. Uji Viskositas. Uji viskositas gel dilakukan dengan menggunakan alat viscometer Cup and $B o b$. Viskositas dibaca pada skala dari rotor yang digunakan. Satuan yang digunakan menurut JLS 28809 standar viskositas yang telah dikalibrasi adalah desipaskal-second (d Pas). Pengujian ini direplikasi sebanyak tiga kali. Pengujian pertama dilakukan setelah sediaan gel dibuat dalam satu hari. Sediaan gel kemudian disimpan dan diuji lagi viskositasnya setelah satu bulan.

4. Uji Daya Sebar Gel. Uji ini dilakukan dengan menggunakan alat-alat seperti sepasang cawan petri, anak timbang gram dan stop watch kemudian dilakukan dengan cara menimbang 0,5 g gel, diletakkan dengan kaca yang lainnya, diletakkan kaca tersebut di atas massa gel dan dibiarkan 1 menit. Diameter gel yang menyebar (dengan mengambil panjang rata-rata diameter dari beberapa sisi) diukur, kemudian ditambahkan 50 g, 100 g, 150 g, 200 $\mathrm{g}$, sebagai bahan tambahan, setiap penambahan beban didiamkan selama 1 menit sesudah itu dicatat diameter gel yang menyebar seperti sebelumnya. Pengujian dilakukan setelah sediaan gel dibuat dalam satu hari.

5. Uji Daya Lekat Gel. Uji ini dilakukan dengan menggunakan alat- alat seperti alat tes melekat gel. Dua gelas obyek, stopwatch, anak timbangan gram dan dilakukan dengan cara melekatkan gel secukupnya di atas gelas obyek yang lain di atas tersebut kemudian ditekan dengan beban $500 \mathrm{~g}$ selama 5 menit kemudian pasang obyek gelas pada alat tes kemudian dilepaskan beban berat $20 \mathrm{~g}$ dan dicatat waktu sampai kedua obyek tersebut terlepas diulangi cara di atas pada masing-masing formula sebanyak 3 kali. Pengujian dilakukan setelah sediaan gel dibuat dalam satu hari. 


\section{JURNAL INOVASI \\ FARMASI INDONESIA}

(JAFI)

6. Uji pH Gel. Uji ini dilakukan dengan menggunakan alat pH meter dengan cara mencelupkan batang detektor ke dalam larutan gel yang terbuat dari 1 gram gel ditambah $9 \mathrm{~mL}$ aquades. Pengujian dilakukan setelah gel dibuat dalam satu hari.

\section{Penentuan Formula Optimum}

Penentuan formula optimum menggunakan metode Simplex Lattice Design. Dengan sebuah program dari Software Design Expert versi 8.0.6.1 dapat ditentukan formula optimum gel yang mempunyai stabilitas baik.

\section{Uji Aktivitas Penangkap Radikal}

1. Pembuatan Larutan DPPH. Menimbang seksama $15,8 \mathrm{mg} \mathrm{DPPH}$, kemudian dilarutkan dengan metanol p.a sampai tanda pada labu takar $100,0 \mathrm{~mL}$, sehingga diperoleh konsentrasi $0,4 \mathrm{mM}$, lalu labu takar dilapisi aluminum foil.

2. Penentuan Panjang Gelombang Maksimal. Larutan DPPH $0,4 \mathrm{mM}$ sebanyak $1,0 \mathrm{~mL}$ ditempatkan di dalam vial 5,0 mL, kemudian ditambah metanol p.a sampai tanda, diukur absorbansinya pada panjang gelombang 500-550 nm.

3. Penentuan Operating Time. Larutan stock DPPH $0,4 \mathrm{mM}$ diambil sebanyak $1,0 \mathrm{~mL}$ dan ditempatkan pada vial 5,0 mL, ditambahkan larutan ekstrak sampai tanda batas, kemudian divorteks selama 30 detik. Penentuan operating time dilakukan pada $\lambda$ maksimum dengan interval waktu 5 menit sampai didapat absorbansi yang stabil dan tidak terlihat adanya penurunan absorbsi. Waktu yang diperoleh digunakan juga untuk vitamin C.

4. Uji Aktivitas Penangkap Radikal. Ekstrak dan gel diuji aktivitas penangkapan radikal terhadap radikal bebas DPPH yang telah diukur absorbansinya pada $\lambda$ maks setelah waktu yang didapat dari operating time. Preparasi larutan yang akan diukur sebagai berikut: 50,0 $\mathrm{mL}$ sediaan gel tanaman anting-anting, kemudian dilarutkan dengan etanol sampai tanda batas pada labu takar $50,0 \mathrm{~mL}$ dan $2,0 \mathrm{mg}$ vitamin $\mathrm{C}$ dilarutkan dengan aquades sampai tanda batas pada labu takar 2,0 mL ditambahkan 1,0 larutan DPPH 0,4 mM, diinkubasi selama 30 menit kemudian dibaca absorbansinya pada $\lambda$ maksimal. Pengujian dilakukan pada hari pertama.

\section{HASIL DAN PEMBAHASAN}

\section{Identifikasi Kandungan Senyawa Dalam Tanaman Anting-Anting}

Identifikasi senyawa dengan KLT pada penelitian kali ini dilakukan pada ekstrak tanaman anting-anting. Uji identifikasi kandungan senyawa dalam penelitian ini meliputi uji vitamin $\mathrm{C}$, flavonoid, dan tanin.

Tabel 3. Hasil Identifikasi KLT Ekstrak Tanaman Anting-Anting

\begin{tabular}{ccccccc}
\hline Senyawa & Fase diam & Fase gerak & $\begin{array}{c}\text { Pereaksi } \\
\text { semprot }\end{array}$ & Pustaka & $\begin{array}{c}\text { Hasil } \\
\text { percobaan }\end{array}$ & Rf \\
\hline Vitamin C & $\begin{array}{c}\text { Silika gel GF } \\
254\end{array}$ & $\begin{array}{c}\text { n- butanol : asam } \\
\text { asetat : air }(4: 1: 5)\end{array}$ & Dragendorf & Orange & Orange & 0,26 \\
\hline Flavonoid & $\begin{array}{c}\text { Silika gel GF } \\
254\end{array}$ & $\begin{array}{c}\text { n- butanol : asam } \\
\text { asetat : air }(4: 1: 5)\end{array}$ & $\begin{array}{c}\text { Larutan } \\
\text { sitro borat }\end{array}$ & Kuning & $\begin{array}{c}\text { Hijau } \\
\text { kekuningan }\end{array}$ & 0,38 \\
Tanin & $\begin{array}{c}\text { Silika gel GF } \\
\text { n- heksan : etil } \\
\text { asetat }(3: 7)\end{array}$ & $\mathrm{FeCl}_{3} 1 \%$ & $\begin{array}{c}\text { Kuning } \\
\text { kehitaman }\end{array}$ & $\begin{array}{c}\text { Kuning } \\
\text { kehitaman }\end{array}$ & 0,95 \\
\hline
\end{tabular}


(JAFI)

Dari hasil identifikasi ini bisa disimpulkan bahwa tanaman anting-anting mengandung vitamin C, flavonoid, dan tanin sebagai senyawa antioksidan dan ekstrak yang digunakan benarbenar ekstrak tanaman anting-anting.

\section{Hasil Pengujian Sifat Fisik Gel Tanaman Anting-Anting}

Tabel 4. Hasil Viskositas Sediaan Tanaman Anting-Anting

\begin{tabular}{cccc}
\hline Sifat fisik gel & Formula 1 & Formula 2 & Formula 3 \\
\hline Viskositas (d Pas) & 500 & 300 & 50 \\
\hline Daya sebar (Cm) & 3,63 & 4,37 & 13,17 \\
\hline Daya lekat (detik) & 94,67 & 44,67 & 5 \\
\hline
\end{tabular}

1. Uji Viskositas: Berdasarkan data pada tabel di atas didapatkan persamaan viskositas dari persamaan Simplex Lattice Design dengan menggunakan program Design Expert sebagai berikut :

$Y=503,33(A)+50(B)+93,33(A)(B)$

Berdasarkan data pada tabel di atas didapatkan profil viskositas dari persamaan Simplex Lattice Design dengan menggunakan program, digambarkan sebagai berikut :

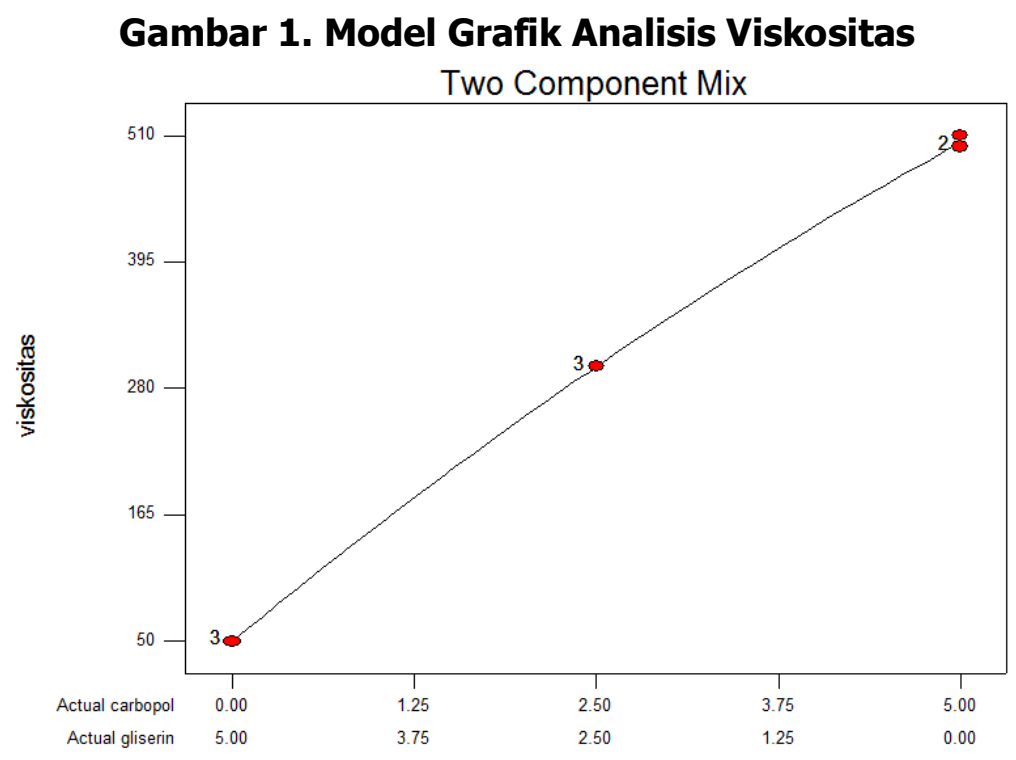

Gambar di atas menunjukkan bahwa semakin banyak proporsi carbopol dan semakin sedikit proporsi gliserin yang ditambahkan dalam formula akan menaikkan viskositas gel. Koefisien carbopol lebih besar dari pada gliserin dapat diartikan bahwa pengaruh carbopol lebih besar dalam peningkatan viskositas gel dibanding gliserin. Kombinasi antara carbopol dan gliserin bernilai positif yang berarti Kombinasi antara carbopol dan gliserin juga mengakibatkan peningkatan viskositas. 


\section{JURNAL INOVASI

(JAFI)

2. Daya Sebar: Daya sebar adalah parameter yang penting dalam penelitian untuk menilai kemampuan gel dalam menyebar. Sediaan gel dapat dikatakan memenuhi sifat mekanik yang optimal, jika sediaan mudah dikeluarkan dari wadah dan memiliki daya sebar yang baik pada kulit ketika sediaan diaplikasikan sehingga memberikan kenyamanan penggunaan oleh konsumen (Fitriana, 2018). Daya sebar yang baik untuk gel antara 5-7 Cm (Sayuti, 2015). Jadi daya sebar yang baik haya didapatkan pada formula 3 sebesar $13,17 \mathrm{Cm}$.

Berdasarkan data pada tabel di atas didapatkan persamaan daya sebar dari persamaan. Simplex Lattice Design dengan menggunakan program Design Expert sebagai berikut :

$$
Y=3,63(A)+13,17(B)-16,13(A)(B)
$$

Berdasarkan data pada tabel di atas didapatkan profil daya sebar dari persamaan Simplex Lattice Design dengan menggunakan program, digambarkan sebagai berikut :

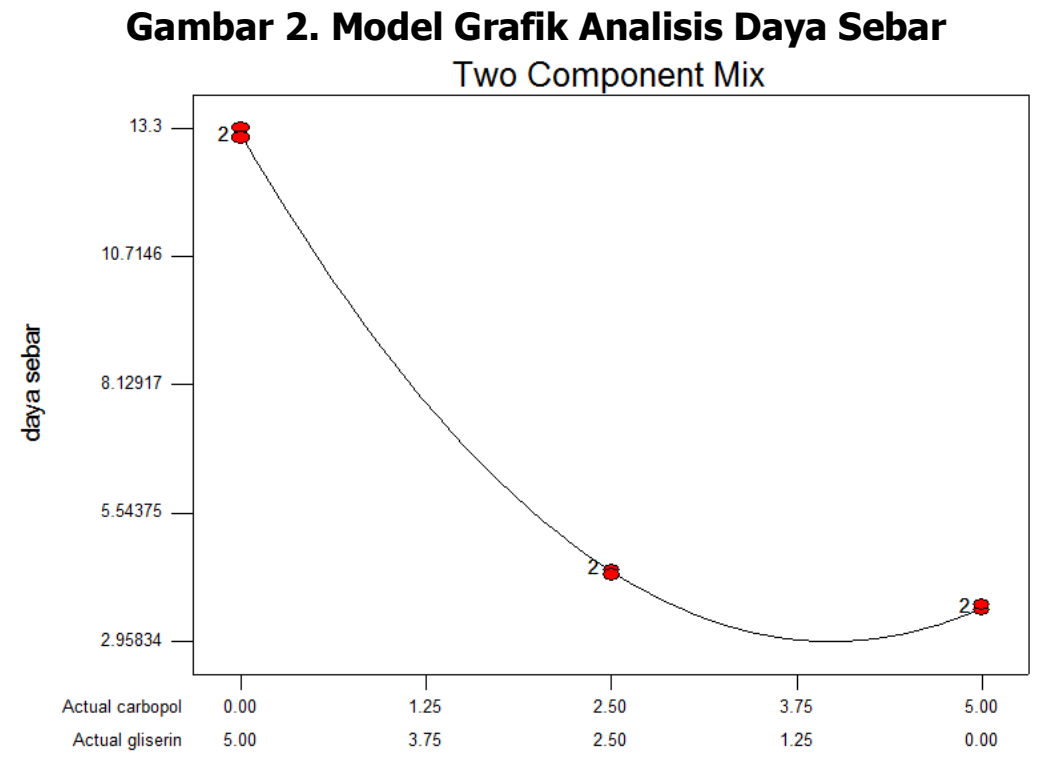

Gambar di atas menunjukkan bahwa semakin sedikit proporsi carbopol dan semakin banyak proporsi gliserin yang ditambahkan dalam formula akan meningkatkan daya sebar gel. Koefisien gliserin lebih besar dari pada carnopol dapat diartikan bahwa pengaruh gliserin lebih besar dalam peningkatan daya sebar gel dibanding gliserin. Kombinasi antara carbopol dan gliserin bernilai negatif yang berarti kombinasi antara carbopol dan gliserin dapat mengakibatkan penurunan daya sebar.

3. Daya Lekat: Kemampuan daya lekat gel akan mempengaruhi efek terapi. Semakin lama kemampuan gel melekat pada kulit, maka gel dapat memberikan efek terapi yang lebih lama. Daya lekat sediaan gel yang baik adalah tidak kurang dari 4 detik (Yati et al., 2018).

Berdasarkan Tabel 4. uji daya lekat formula 1,2, dan 3 memiliki daya lekat yang baik. Berdasarkan data pada tabel di atas didapatkan persamaan daya lekat dari persamaan Simplex Lattice Design menggunakan program Design Expert sebagai berikut :

$$
Y=94,67(A)+7,0(B)-24,67(A)(B)
$$




\section{JURNAL INOVASI}

(JAFI)

Berdasarkan data pada Table 4. didapatkan profil daya lekat dari persamaan Simplex Lattice Design dengan menggunakan program, digambarkan sebagai berikut :

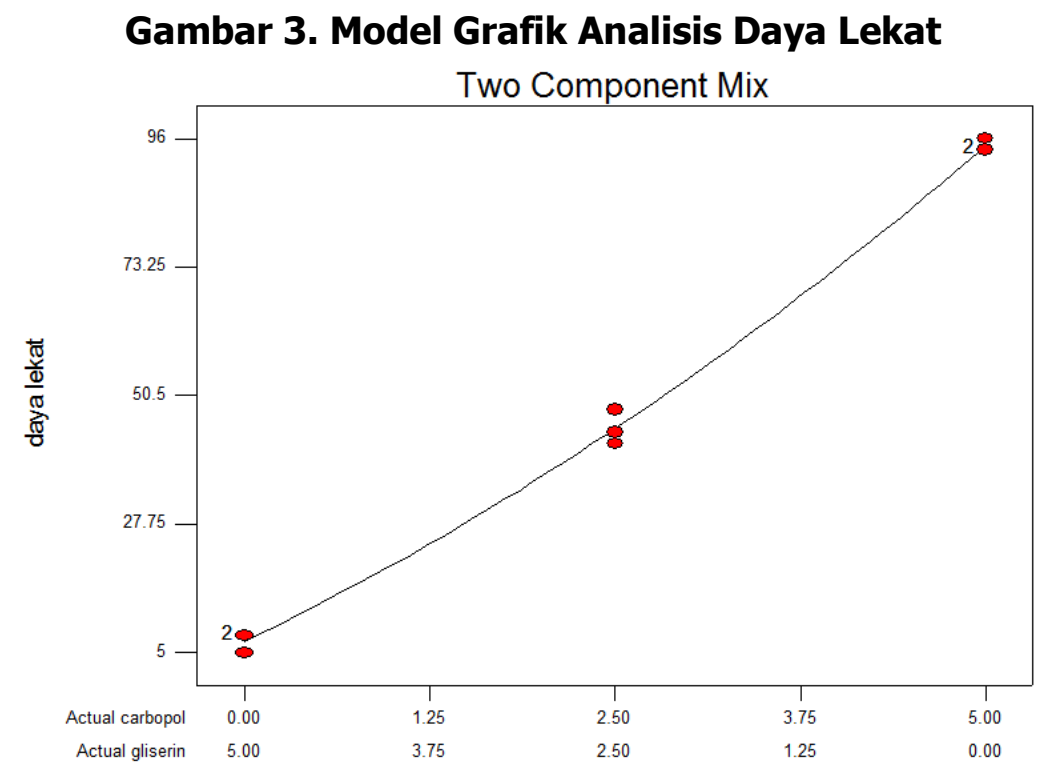

Gambar di atas menunjukkan bahwa semakin banyak proporsi carbopol dan semakin sedikit proporsi gliserin yang ditambahkan dalam formula akan menaikkan daya lekat gel. Koefisien carbopol lebih besar dari pada gliserin dapat diartikan bahwa pengaruh carbopol lebih besar dalam peningkatan daya lekat gel dibanding gliserin. Kombinasi antara carbopol dan gliserin bernilai negatif yang berarti Kombinasi antara carbopol dan gliserin juga mengakibatkan penurunan daya lekat

\section{Penetapan Profil Formula Optimum}

Optimasi gel dalam penelitian ini didasarkan pada pengujian terhadap uji viskositas, uji daya lekat, dan uji daya sebar menggunakan program design- expert 8.0.6.1.

Berdasarkan program didapatkan formula optimum yang diprediksi dari daerah optimum tersebut dengan komposisi carbopol $1,18 \mathrm{~g}$ dan gliserin 3,82 g. Dari program ditemukan nilai optimum dengan prediksi 0,302. Program juga memprediksi untuk respon viskositas sebesar $173,78 \mathrm{dPas}$, daya sebar sebesar $8,01 \mathrm{~cm}$, dan daya lekat sebesar 23,24 detik.

\section{Hasil Pengujian Sifat Fisik Gel Optimum Tanaman Anting-Anting}

1. Organoleptis. Uji organoleptis dilakukan untuk mendiskripsikan warna, bau, dan konsistensi. Hasil pengamatan terhadap uji organoleptis gel optimum dapat dilihat pada Tabel $5 .$.

2. Homogenitas. Uji homogenitas gel dilakukan untuk mengetahui apakah ekstrak tanaman anting-anting dan semua bahan dalam sediaan sudah homogen atau belum. Hasil pengamatan terhadap uji homogenitas gel optimum didapatkan gel yang homogen. Semakin 


\section{JURNAL INOVASI}

(JAFI)

baik homogenitas gel maka akan didapatkan dosis gel yang sama dan merata dalam pemakaiannya.

Gambar 4. Model Grafik Analisis Formula Optimum

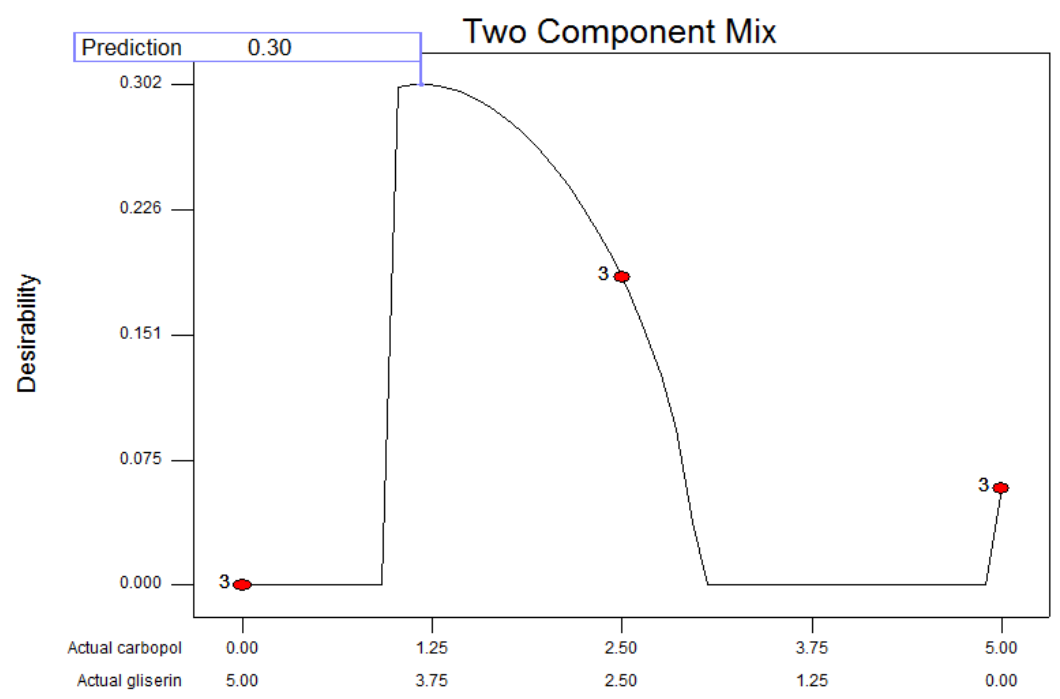

Tabel 5. Hasil Organoleptis Gel Optimum Tanaman Anting-Anting

\begin{tabular}{cc}
\hline Pemeriksaan & Pengamatan \\
\hline Warna & Hijau kecoklatan \\
Bau & Khas \\
Konsistensi & Agak kental \\
\hline
\end{tabular}

3. Uji pH. Uji pH dilakukan agar dapat diketahui bahwa gel yang didapat bersifat asam atau basa. Uji ini dilakukan dengan menggunakan alat $\mathrm{pH}$ meter dengan penunjuk digital. $\mathrm{pH}$ sediaan gel yang baik yaitu $\mathrm{pH}$ yang sama dengan $\mathrm{pH}$ kulit yaitu 4,5-7. Hal ini bertujuan agar tidak menimbulkan iritasi. Jika sediaan memiliki pH yang lebih tinggi atau terlalu basa maka akan mengakibatkan kulit menjadi bersisik, sedangkan jika terlalu rendah atau asam maka akan menimbulkan iritasi pada kulit (Fitriansyah et al., 2016). Hasil pengamatan terhadap uji $\mathrm{pH}$ gel optimum didapatkan nilai $\mathrm{pH}$ sebesar 5,16. yang menunjukkan bahwa gel optimum tanaman anting-anting dikatakan baik.

\section{Hasil Pengujian Aktivitas Antioksidan Gel Optimum Tanaman Anting-Anting}

Tabel 6. Hasil Aktivitas Antioksidan Dari Gel Optimum Tanaman Anting-Anting

\begin{tabular}{cc}
\hline Sampel & $\mathrm{IC}_{50}(\mathrm{ppm})$ \\
\hline Gel optimum tanaman anting-anting & 164,58 \\
Vitamin C & 3,18 \\
\hline
\end{tabular}

Penelitian aktivitas antioksidan gel tanaman anting-anting dengan komposisi carbopol 940 dan gliserin optimum menggunakan metode DPPH. Uji aktivitas antioksidan yang dilakukan 


\section{JURNAL INOVASI \\ FARMASI INDONESIA}

(JAFI)

menggunakan metode serapan radikal DPPH. Metode ini dipilih karena merupakan metode yang tergolong sederhana, mudah dan menggunakan sampel dalam jumlah yang sedikit dengan waktu yang relatif singkat (Aji, 2014). Parameter yang digunakan untuk mengetahui aktivitas antioksidan adalah $\mathrm{IC}_{50}$ yang diartikan sebagai konsentrasi senyawa antioksidan yang menyebabkan hilangnya $50 \%$ aktivitas $\mathrm{DPPH}$, semakin kecil nilai $\mathrm{IC}_{50}$ maka aktivitasnya sebagai antioksidan akan semakin tinggi.

Menurut Molyneux (2004), suatu senyawa dikatakan sebagai antioksidan sangat kuat jika nilai IC I0 $_{50}$ urang dari 50 ppm, kuat untuk IC $_{50}$ bernilai $50-100$ ppm, sedang jika IC $C_{50}$ bernilai 100$150 \mathrm{ppm}$, dan jika $\mathrm{IC}_{50}$ bernilai $150-200 \mathrm{ppm}$ maka aktivitas antioksidan yang dimiliki sangat lemah. Hasil yang didapat dari penelitian ini bahwa aktivitas antioksidan gel optimum tanaman anting-anting digolongkan lemah dengan harga $\mathrm{IC}_{50}$ sebesar $164,58 \mathrm{ppm}$. Hal ini diduga karena komposisi ekstrak anting-anting yang hanya $10 \%$ dari total formula masih kurang efektif.

\section{KESIMPULAN}

Kombinasi gel anting-anting yang optimum yaitu carbopol $1,18 \mathrm{~g}$ dan gliserin $3,82 \mathrm{~g}$ sebagai basis dengan metode Simplex Lattice Design yaitu Carbopol dan $\mathrm{IC}_{50}$ gel tanaman antinganting sebesar 164,58 ppm.

\section{UCAPAN TERIMA KASIH}

Ucapan terimakasih kepada Universitas Kadiri dan LP3M atas dukungan dan bantuan dana penelitian, Laboratorium Farmasi Fakultas Ilmu Kesehatan Universitas Kadiri, serta seluruh yang mendukung dan membantu dalam penelitian.

\section{DAFTAR PUSTAKA}

Aji, R.M.. 2014. Uji Aktivitas Antioksidan Pada Ekstrak Daging Lidah Buaya (Aloe Vera) Menggunakan Metode DPPH (1,1-Diphenyl-2-Picrylhidrazyl). Repositori UIN Syarif Hidayatullah. Jakarta.

Fitriana, Y., Ittiqo', D.H.. 2018. Optimasi Formula Gel Serbuk Daging Limbah Tomat (Lycopersicum Asculentum Mill.) Dan Uji Ativitas Terhadap Lama Penyembuhan Luka Eksisi Pada Kelinci. Universitas Muhammadiyah Mataram: Jurnal Ulul Albab. 22(1): 20-26.

Fitriansyah, S.N., Sohadi, W., Hermayanti, C.. 2016. Formulasi Dan Evaluasi Spray Gel Fraksi Etil Asetat Pucuk Daun Teh Hijau (Camelia Sinensis [L.] Kuntze) Sebagai Antijerawat. PHARMACY. 13(2).

Halimah, N.. 2010. Uji Fitokimia dan Uji Toksisitas Ekstrak Tanaman Anting-Anting (Acalypha indica L.) Terhadap Larva Udang Artemia salina Leach. Skripsi Tidak Diterbitkan. Malang: Jurusan Kimia Fakultas Sains dan Teknologi Universitas Islam Negeri Maulana Malik Ibrahim Malang.

Ismail, I., Handayany, G., Paturusi, A., Ratnasar,i W.. 2014. Formulasi Dan Uji Efektifitas Antioksidan Krim Ekstrak Etanol Korteks Kayu Jawa (Lannea Coromandelica Hout Merr.) Dengan Metode Dpph. Jurnal Farmasi . 2(3).

Lisdawati, V.. 2002. Berdasar Uji Penampisan Farmakologi Pada Buah Mahkota Dewa. Fakultas Kedokteran. Yogyakarta: Universitas Gajahmada.

Molyneux, P.. 2004. The Use Of The Stable Free Radical Diphenylpicrylhydrazyl (DPPH) For Estimating Antioksidan Activity, Songklanakarin: Journal Science Technology. 26(2): 211219. 
(JAFI)

Purwanto, Mufrod, NSP, S.A.. 2013. Aktivitas Antioksidan Krim Ekstrak Sari Tomat (Solanum Lycopersicum L.). Universitas Gadjah Mada Yogyakarta Indonesia: Traditional Medicine Journal. 18(3) : 132-140.

Rahmadhani. 2017. Formulasi Sediaan Gel Ekstrak Ashitaba (Angelica Keiskei) Sebagai Antioksidan Dengan Kombinasi Gelling Agent Karbopol 940 Dan Cmc-Na Yang Diuji Dengan DPPH. Skripsi Thesis. Universitas Setya Budi Surakarta.

Rowe, R., Sheskey, P., Waller, P.. 2006. Handbook of Pharmaceutical Excipients, Edisi keempat. Washington DC: Pharmaceutical Press and American Pharmacist Associations.

Sayuti, N.A.. 2015. Formulasi dan Uji Stabilitas Fisik Sediaan Gel Ekstrak Daun Ketapang Cina (Cassia alata L.). Jurnal Jurusan Jamu, Poltekes Kemenkes, Surakarta.

Voigt, R.. 1995. Buku Pelajaran Teknologi Farmasi. Edisi V., N. Soecandhi SN, Widianto MB. Penerjemah; Yogyakarta: Universitas Gajah Mada Press, terjemahan dari: Lerburch der Pharmaceutischen Technology.

Yati, K., Mahdi, J., Misri, Mardiastuti,. Lusi, P.D.. 2018. Pengaruh Variasi Konsentrasi Hidroxy Methyl Cellulose (HPMC) Terhadap Stabilitas Fisik Gel Ekstrak Tembakau (Nikotiana tabacum L.) dan Aktivitasnya Terhadap Staphyllococcus aureus. Jurnal Fakultas Farmasi dan Sains, Universitas Muhammadiyah Prof. DR. HAMKA. Jakarta. 